\title{
Assessment of Monoterpene Components in Wild Rose Petals Extract
}

\author{
Koval Inna*1 and Rubtsova Olena ${ }^{2}$ \\ ${ }^{1}$ Laboratory of Medical Botany of M.M. Gryshko National Botanical Garden of National Academy of Sciences of \\ Ukraine, Kyiv 01014, Ukraine. \\ ${ }^{2}$ Department of Landscape Construction of M.M. Gryshko National Botanical Garden of National Academy of \\ Sciences of Ukraine, Kyiv 01014, Ukraine. \\ *Corresponding Author Email: inna.kyiv@gmail.com \\ Received 17 February 2020, Revised 11 November 2020, Accepted 20 November 2020
}

\begin{abstract}
The content, component composition, and main directions of the use of monoterpenes of wild rose petals compounds are considered in the research. The study on six wild rose species was carried out in the collection of M.M. Gryshko National Botanical Garden of the National Academy of Sciences of Ukraine. Volatile organic compounds were isolated by steam distillation, and their determination was performed by means of gas chromatography. R. rugosa petals contained the highest number of monoterpenoids, while $R$. canina petals - the lowest. In our research twentyone different (acyclic, monocyclic, bicyclic) monoterpenoids were identified, including alcohols, aldehydes, ethers, and ketones. All groups of monoterpenoids are biologically active substances and have a significant effect on the aroma of the studied plants.
\end{abstract}

Keywords: Essential oil, Wild rose, Petals, Monoterpenoids, Biologically active substances, Weather conditions

\section{Introduction}

The most famous and expensive essential oil in the world is rose oils, which have been known since the time of the ancient civilizations of Egypt, India, Greece, Turkey, but Iran is considered the homeland. Nowadays, the largest number of essential oil (rose) is grown in Bulgaria. The essential rose oils are widely used for the production of high-quality perfumes (Group A and Extra). The aroma of petals depends on the type and variety of rose hips or roses and is genetically determined [1]. The composition of the essential oil depends on the place of growing plants and the method of oil obtaining [2, 3]. The composition of rose oils has been thoroughly studied $[4,5]$. But most of the researchers pay attention to the accumulation of dominant components in essential rose and rose hips oils [6,7]. Unlike essential oil of rose, the composition of substances that are contained in the petals of wild rose is just beginning to be studied. In recent years, more and more attention has been paid to these issues [8-11].

Volatile organic substances responsible for the aroma of plants also have different biological activities (antiseptic, antispasmodic, tonic, antioxidant, anticarcinogenic, and others) [12-14]. It is established that terpenoids are responsible for the aroma of plants and have different pharmacological properties [15]. A significant percentage of the total terpenoids are 
monoterpene compounds [16]. They are present in almost all essential oils and are considered their safest components. Monoterpenes hydrocarbons and $\alpha$ - and $\gamma$ terpenes are the most important components of essential oils, which have high antioxidant activity and inhibitory effect on pathogens $[17,18]$.

It was revealed that plants of various forms differ in the percentage of the main components of essential oils. The dependence of the yield of essential oil on temperature conditions, on the phase of development and age of plants, as well as on the daily course of accumulation of essential oil has been shown [19].

Despite the centuries-old experience of using wild roses and rose petals, unfortunately, the issue of the component composition of terpenoid compounds, in particular, monoterpenoids of wild rose petals, has not been adequately studied. Given the dominant content of these compounds in the composition of the essential oils, the lability from the growing conditions, as well as the value of individual components from the point of view of practical use, the studies of monoterpenoids wild rose petals are a very topical issue.

The purpose of this research was to study the monoterpene compounds of rose petals of the rose garden collection of M.M. Gryshko National Botanical Garden of NAS of Ukraine to determine the component composition and percentage ratio in the conditions of the Forest-Steppe of Ukraine, taking into account the functional effect of the components.

\section{Materials and Methods}

The objects of the research were the wild rose species of $-R$. rouletii Correvon.,
$R$. multiflora Thunb., $R$. spinosissima L., $R$. canina L., $R$. centifolia L., $R$. rugosa Thunb. The wild roses grow in a homogeneous environment at the rose garden (the Rosarium collection site) of M.M. Gryshko National Botanical Garden of NAS of Ukraine according to the classification of wild roses by Khrzhanovskiy [20] that we used, these species belong to three subgenera and five sections: Subgenera Stylorhodon Dumortier, Section Synstylae DC. - $R$. multiflora Thunb., $R$. rouletii Correvon.; Subgenera Cynorhodon Dumortier, Section Caninae Crep.; Subsection Eucaninae Crep. - R. canina L.; Section Rugosa Chrshan. - R. rugosa Thunb.; Section Gallicanae DC. R. centifolia L.; Subgenera Chamaerhodon Dumortier., Section Pimpinellifoliae DC. R. spinosissima L. [21].

Samples for research (flower petals) were taken in the morning time ( $8 \mathrm{am})$ during the phase of mass flowering (May).

\section{Extraction of Oil}

The research on the determination of organic volatiles was carried out on the basis of the National Institute of Grape and Wine "Magarach" in 2013. The organic volatiles were isolated by the conventional method steam distillation. Samples of flower petals $(500 \mathrm{mg}$ ) were placed in a $20 \mathrm{~mL}$ vial containing $10 \mathrm{~mL}$ of water to isolate the essential oil and to establish its qualitative and quantitative composition. The vial was placed in a heating block, which was connected with a cooled receiver vial. The volatiles were distilled off by steam for two hours. During distillation, the volatiles were adsorbed on the inner surface of the reflux condenser. The adsorbed substances were washed after cooling the system. The wash was concentrated by purging $(100 \mathrm{~mL} / \mathrm{min})$ with pure nitrogen to a final volume of $10 \mu \mathrm{L}$ of extract, which was completely removed by 
chromatographic syringe. Tridecane was added to the samples of flower petals as an internal standard (50 mg per sample), which was then used for calculations.

\section{Gas Chromatographic Analysis}

The volatiles were determined using Agilent Technologies 6890/ 5973 GC MSD System. Analysis conditions: chromatographic column - DB-5 capillary, 30 $\mathrm{m}$ length and $0.25 \mathrm{~mm}$ diameter. Helium was used as a carrier gas at a rate of $1.2 \mathrm{~mL} / \mathrm{min}$. The temperature of the sample inlet heater was $250{ }^{\circ} \mathrm{C}$ by temperature-programmed heating (from 50 to $320^{\circ} \mathrm{C}$ ) of the sample vial with a speed of $4^{\circ} \mathrm{C} / \mathrm{min}$. To identify the components, we used the NIST 05 and WILEY 2007 mass spectral libraries with a total number of spectra of more than 470,000 in combination with AMDIS and NIST identification programs. Samples were introduced into the chromatographic column in splitless mode, which made it possible to increase significantly (10-20 times) the sensitivity of the chromatography method. The sample injection rate was $1.2 \mathrm{~mL} / \mathrm{min}$ within $0.2 \mathrm{~min}$. The internal standard method was used for the quantitative calculations [22]. Percentage of the components were computed using Excel. GC chromatograms of organic volatile substances in samples of wild rose petals are illustrated in Fig. 1.

Abundanoe

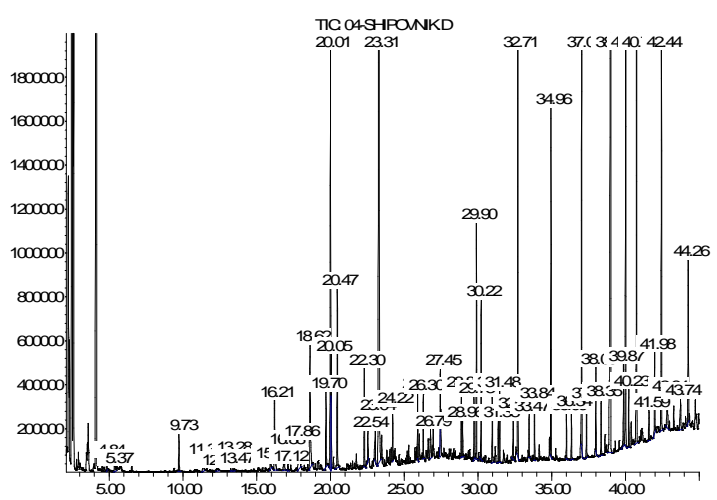

(a) $R$. roulettii
Abundance

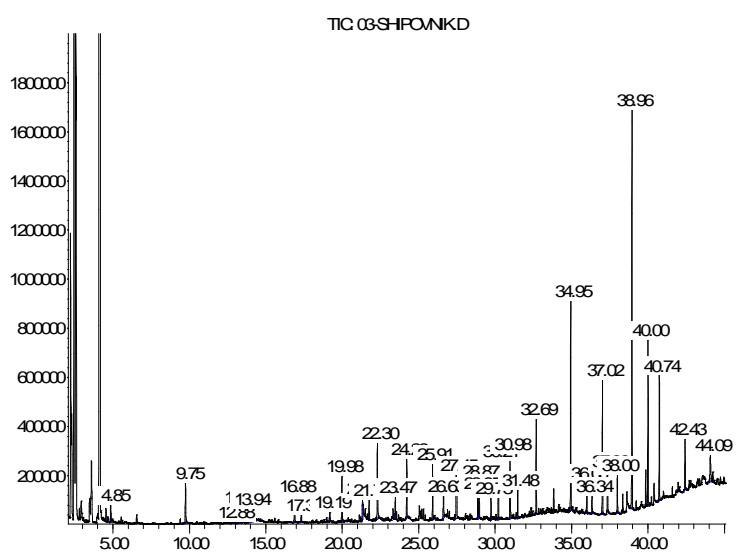

Times $\rightarrow$ R. multiflora
(b) R.

Abundance

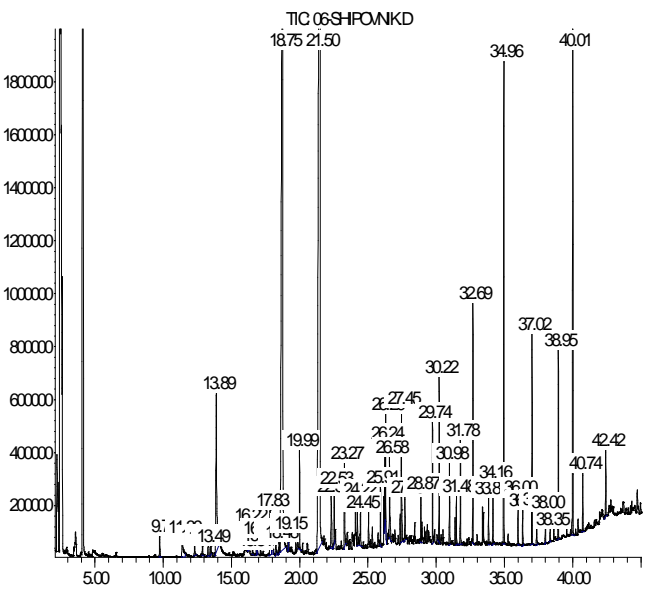

Time $\rightarrow$

(c) R. spinosissima

Abundance

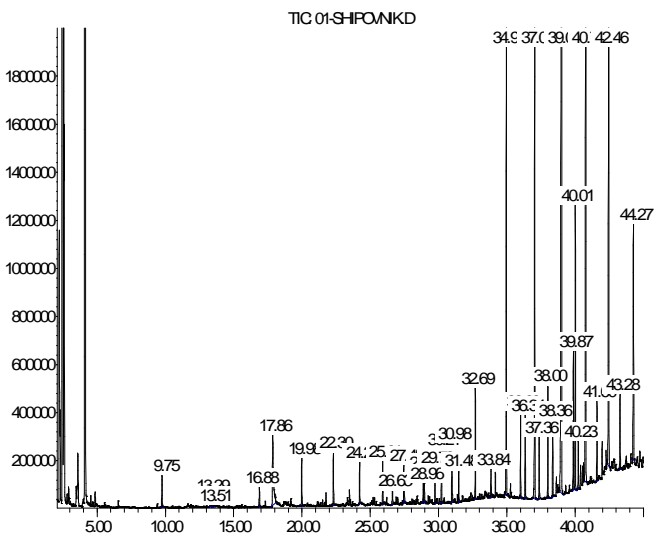

(dires $\rightarrow$ R. canina
(d) 


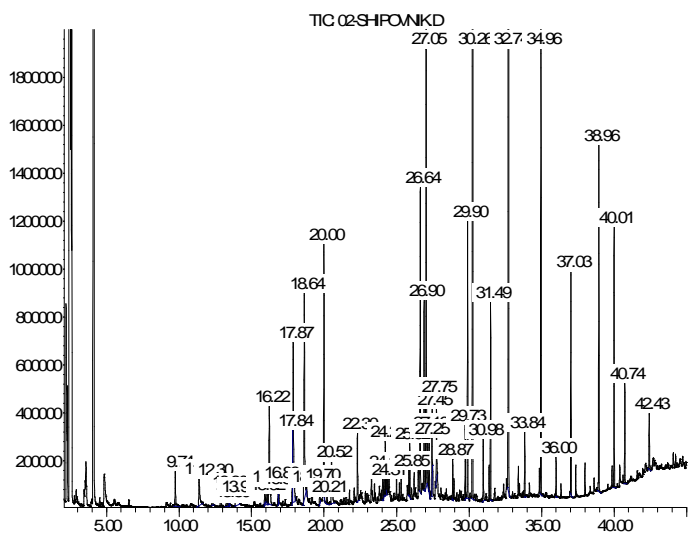

(e) $R$. centifolia

Abundance

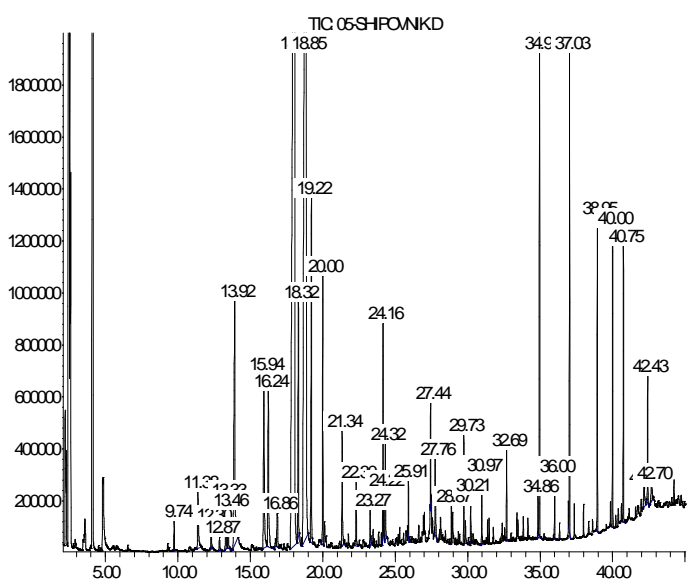

Time $\rightarrow$
(f) $R$. rugosa

Figure 1. GC chromatograms of the determined organic volatile substances in wild rose petals

\section{Research Period Conditions}

It has been confirmed that in the regulation of processes of accumulation and formation of the component composition of essential oils the leading role belongs to weather conditions of the growing season [23, 24]. Therefore, we present the weather conditions of the year of research. Based on the data of the Ukrainian Hydrometeorological Center (the Table of meteorological observations, TMS-84), climographs were developed according to the Gossen-Walter method, characterizing the conditions prevailing during that year $[25,26]$. Thanks to climographs, deviations of the temperature $\left({ }^{\circ} \mathrm{C}\right)$ regime and precipitation $(\mathrm{mm})$ are clearly visible from long-term average indicators during the year of research. According to the nature of the temperature conditions, the year of 2013 research season turned out to be close to the long-term average indicators, but from March to December, the average monthly temperatures exceeded the long-term average indicators by $2-3{ }^{\circ} \mathrm{C}$. As for precipitation, it differed sharply from the long-term average indicators, the lack of precipitation in one month alternated with excessive precipitation in the next month (Fig. 2).

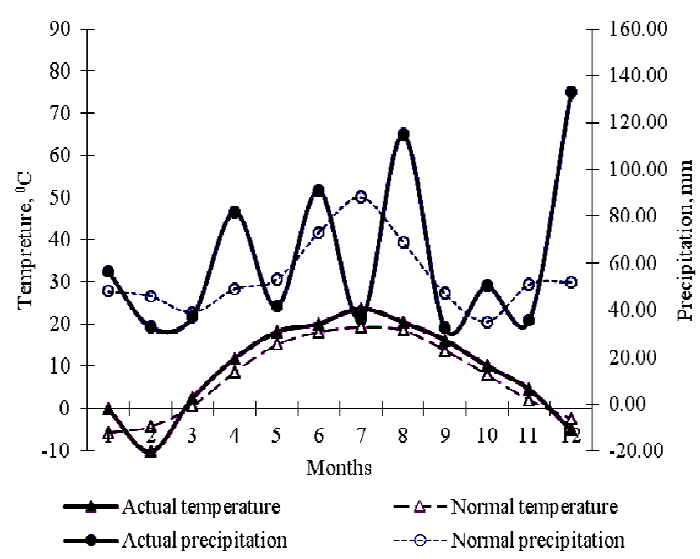

Figure 2. Climographs of precipitation and temperature for Kyiv, Ukraine, 2013

\section{Results and Discussion}

Based on the data obtained, twentyone monoterpenoids were identified (Table 1). It was established that the studied samples had a different composition of monoterpenoids, which were found in rose petals in the amount of one compound in $R$. canina, three compounds $-R$. multiflora, eight compounds $-R$. rouletii, nine compounds $-R$. centifolia, twelve compounds - R. spinosissima, and thirteen compounds $-R$. rugosa. 
Table 1. Groups of monoterpenoids obtained from wild rose petals*.

\begin{tabular}{|c|c|c|c|c|c|c|}
\hline \multirow[t]{2}{*}{ Organic Volatiles } & $\begin{array}{c}R . \\
\text { roul- } \\
\text { ettii }\end{array}$ & $\begin{array}{c}R . \\
\text { multi- } \\
\text { flora }\end{array}$ & $\begin{array}{c}R . \\
\text { spinos- } \\
\text { issima }\end{array}$ & $\begin{array}{c}R . \\
\text { can- } \\
\text { ina }\end{array}$ & $\begin{array}{c}R . \\
\text { centi- } \\
\text { folia }\end{array}$ & $\underset{\text { rugosa }}{R .}$ \\
\hline & \multicolumn{6}{|c|}{ Acyclic Monoterpene (\%) } \\
\hline 1,2-Epoxylinalool & - & - & - & - & - & 2.44 \\
\hline cis-Linalool oxide & - & 0.1 & 0.13 & - & - & 0.14 \\
\hline Citronellol & 0.92 & - & 0.3 & 2.56 & 3.44 & 24.35 \\
\hline Ethyl linoleate & 0.38 & - & - & - & - & - \\
\hline Geranial & - & - & 0.24 & - & - & 3.18 \\
\hline Geraniol & 2.37 & - & 24.86 & - & 4.14 & 31.29 \\
\hline Geranyl acetone & - & - & - & - & - & 0.26 \\
\hline Hotrienol & - & - & & - & 0.06 & 0.43 \\
\hline Linalool & - & 1.28 & 0.27 & - & 0.45 & 0.58 \\
\hline Neral & - & - & 0.24 & - & - & 2.34 \\
\hline Nerol & - & - & 1.18 & - & 0.89 & 5.68 \\
\hline $\begin{array}{l}\text { trans-Linalool } \\
\text { oxide }\end{array}$ & - & - & 0.16 & - & 0.45 & 0.22 \\
\hline \multicolumn{7}{|c|}{ Monocyclic Monoterpenes (\%) } \\
\hline$\alpha$-Terpineol & - & 1.75 & 0.11 & - & 0.25 & 0.49 \\
\hline Carvone & - & - & 0.17 & - & - & - \\
\hline $\begin{array}{l}\text { Dihydro-beta- } \\
\text { ionol }\end{array}$ & 18.47 & & - & - & - & - \\
\hline $\begin{array}{l}\text { Dihydro-beta- } \\
\text { ionone }\end{array}$ & 0.69 & - & - & - & - & - \\
\hline Menthol & 1.38 & - & 0.42 & - & 2.14 & 2.08 \\
\hline para-Cymen-8-ol & - & - & 0.08 & - & - & - \\
\hline Piperitone & - & - & - & - & 0.11 & - \\
\hline \multicolumn{7}{|c|}{ Bicyclic Monoterpenes (\%) } \\
\hline Theaspirane A & 1.35 & - & - & - & - & - \\
\hline Theaspirane B & 2.17 & - & - & - & - & - \\
\hline TOTAL & 27.73 & 3.13 & 28.16 & 2.56 & 11.93 & 73.48 \\
\hline
\end{tabular}

* - Tolerance limit was defined as the ratio that causes less than \pm 5 percent interference.

We calculated the relative content of monoterpenoids from the total amount of organic volatiles [27]. The least monoterpenoids were detected in the petals of $R$. canina $-2.56 \%$ and $R$. multiflora $-3.13 \%$. A relatively high number of monoterpene compounds was identified in the samples of $R$. centifolia $-11.93 \%, R$. rouletii $-27.73 \%$, and R. spinosissima $-28.16 \%$. Significantly different number of monoterpenoids were identified in the petals of $R$. rugosa, the content of which amounted to almost $2 / 3$ of all organic volatiles (73.48\%) Fig. 3.
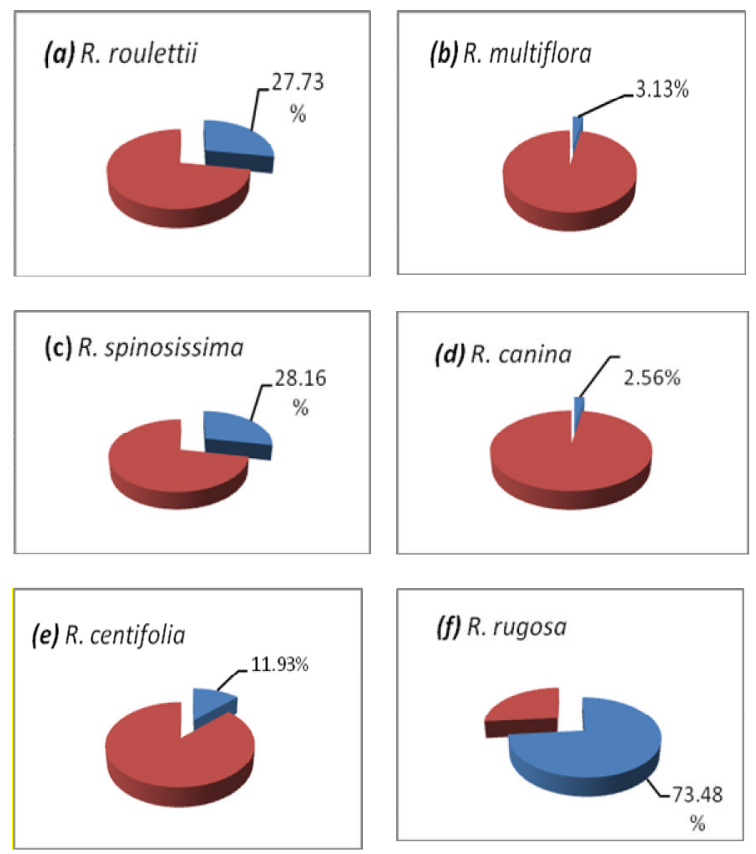

- Monoterpenoids

- Other organic volatiles

Figure 3. Total and monoterpenoids content in wild rose petals

Detected acyclic, monocyclic, bicyclic monoterpenoids include alcohols, aldehydes, esters, and ketones. The main dominant constituents were monoterpene alcohols among which the greatest number were Geraniol (31.29\%) and Citronellol (24.35\%). Monoterpene alcohols are a fairly diverse group. In the wild rose's petals, they are represented by eleven components (alphaTerpineol, Geraniol, Linalool, Menthol, transLinalool oxide, Nerol, para-Cymen-8-ol, Hotrienol, Citronellol, 1,2-Epoxylinalool, cisLinalool oxide). Among the listed monoterpene alcohols there are acyclic and monocyclic compounds. Acyclic compounds are not yet used in medicine, unlike monocyclic monoterpene alcohols, which are widely used as standalone compounds or in mixtures with others. Monoterpene alcohols do not cause skin irritation, are one of the safest components of essential oils. They exhibit a bactericidal, antiviral, and tonic 
effect. In the wild rose's petals, monoterpene alcohols are the most important fraction of monoterpenoids. Aliphatic monoterpene alcohol Linalool (3,7-dimethyl-1,6-octadien3 -ol), is the basis for the formation of other monoterpene alcohols, and in its pure form it has the smell of lily of the valley and a sedative effect on the nervous system. Linalool was found in small quantities in the petals of $R$. spinosissima - $0.27 \%$, $R$. centifolia $-0.45 \%, R$. rugosa $-0.58 \%$, and R. multiflora - $1.28 \%$. Acyclic monoterpenoids were represented in $R$. centifolia petals by trans-Linalool oxide $-0.45 \%$, $R$. rugosa - two compounds, namely cisLinalool oxide $-0.14 \%$ and trans-Linalool oxide $-0.22 \%$; the same compounds of trans-Linalool oxide and cis-Linalool oxide were also observed in small quantities in $R$. spinosissima $(0.13 \%$ and $0.16 \%$, respectively). These compounds were absent in the petals of $R$. rouletii and $R$. canina.

The interaction of Linalool with sulphuric acid produces Terpineol. This monoterpene alcohol was found in small quantities in the petals of $R$. spinosissima $0.11 \%$, R. centifolia - $0.25 \%$, R. rugosa $0.49 \%$. Its quantity in the petals of $R$. multiflora reached $1.75 \%$, however. Interestingly, in all the studied petal samples, Terpineol was contained in the $\alpha$-isomeric form, and not in the form of $\gamma$-isomer, which is more typical of roses. Terpineol has a pleasant aroma that resembles lilac and lily of the valley and is used in aromatic compositions.

When interacting with organic acids, Linalool forms another monoterpene alcohol Geraniol, which has the odour of rose. There is no direct link between the quantities of these alcohols. The undisputed leaders in the quantity of this compound were the petals of $R$. spinosissima $-24.86 \%$ and $R$. rugosa -
$31.29 \%$. A smaller quantity of Geraniol was found in the petals of $R$. rouletii $-2.37 \%$ and $R$. centifolia - 4.14\%. Monoterpenoids Geranial - $3.18 \%$ and Geranyl acetone $0.26 \%$ were found in $R$. rugosa petals.

Nerol is a cis-isomer of Geraniol, which was found in small quantities in $R$. centifolia $-0.89 \%$ and $R$. spinosissima $1.18 \%$, but in $R$. rugosa petals its quantity reached $5.68 \%$. It belongs to aromatic compounds with a delicate smell of roses, used in the aromatic compositions and in the synthesis of other substances, such as Citral.

Citronellol is one of the main monoterpene alcohols, according to which the quality of rose oils is standardized, and it has the smell of rose. A fairly significant quantity of Citronellol in $R$. rugosa petals was noted during its cultivation in China, indicating the genetic determinism of this compound. Citronellol was found in all species except $R$. multiflora. Citronellol was the only monoterpenoid component found in the petals of $R$. canina $-2.56 \%$. Its highest quantity was found in the petals of $R$. rugosa (24.35\%). Citronellol is used as the anti-inflammatory, antimicrobial, antifungal, and repellent agent.

The monocyclic monoterpene alcohol Menthol was found in four species $R$. rugosa, R. spinosissima, R. centifolia, and $R$. rouletii. Menthol has anaesthetic and antiseptic properties and is widely used as a flavouring agent. Its maximum quantities were contained in $R$. centifolia $-2.14 \%$, and minimum $-R$. spinosissima $-0.42 \%$.

Carvone was present in the petals of only $R$. spinosissima in a small quantity $(0.17 \%)$. The enantiomers of this compound have different aromas: $(R)-(-)$-Carvone has a mint odour, while $(S)-(+)$-Carvone - cumin odour. 
Linalool oxidation leads to the formation of Citral. We detected it in the petals of $R$. spinosissima and $R$. rugosa in the form of Z-isomer (cis-isomer) - Neral and $E$ isomer (trans-isomer) - Geranial. It should be noted that Geranial (one of two geometric isomers of Citral) is more oxidized. In an acidic aqueous medium, it is isomerized to Neral, which then forms intermediate alcohols, which, in turn, are oxidized to paracymen-8-ol. This monoterpene alcohol was only contained in the petals of $R$. spinosissima at trace concentrations of $0.08 \%$, which might be the result of oxidation.

The components Neral and Geranial belong to monoterpene aldehydes. The monoterpene aldehydes are the most odorous class. They have an anti-infectious effect, due to the reduction of bacteria and viruses, they could be used as antiseptics and tonic substances. They are not as dangerous as alcohols. Both compounds were found in $R$. spinosissima and R. rugosa. The petals of $R$. spinosissima contain $0.24 \%$ of each of these compounds, in comparison with $R$. rugosa, which petals contain a much higher percentage of Neral $-2.34 \%$, and Geranial $3.18 \%$.

Most essential oils contain esters, but their content is negligible. They balance the nervous system, have anti-inflammatory, fungicidal, and antispasmodic effects. In the wild rose's petals, the esters were represented by two constituents and were found in $R$. rouletii (as Ethyl linoleate $0.38 \%$ ) and R. rugosa (as Geranyl acetone $0.26 \%)$.

Monoterpene ketones were found in small amounts in $R$. spinosissima (Carvone $0.17 \%$ ) and R. centifolia (Piperitone $-0.11 \%$ ). It is known that ketones protect cells and are used in the treatment of skin and for wound healing, enhancing mucus outflow.
Dihydro-beta-ionol (18.47\%), Dihydro -beta-ionone $(0.69 \%)$, Theaspirane A $(1.35 \%)$, and Theaspirane B $(2.17 \%)$ were present only in the petals of $R$. rouletii. These components have a significant effect on the aromatic bouquet of rose oil and together with the other constituents determine the characteristic aroma. This aroma is valued in the field of nutritional supplements due to its natural origin.

\section{Conclusion}

Thus, the studied wild rose's species contain twenty-one acyclic, monocyclic, bicyclic monoterpenoids, accounting for from $2.56 \%$ to $73.48 \%$ of the total volatiles. They have a species-specific composition that could be seen as an additional factor in chemosystematic studies and a supplement to use in pharmacology and perfumery. Of all monoterpene compounds, eleven alcohols, two ketones, two aldehydes, and two esters were identified. R. rugosa petals represented by the richest assortment (thirteen components) contain the highest number of monoterpenoids - $73.48 \%$. The dominant components are monoterpene alcohols Geraniol - 31.29\% and Citronellol - 24.35\%, which are very valuable in their obtaining and future use. $R$. spinosissima and $R$. rouletii have about the same quantitative content of monoterpenoids, but very different in their composition. R. spinosissima is mainly represented by monoterpene alcohols. R. canina petals contain the lowest number of monoterpenoids $-2.56 \%$. All monoterpenoid groups are biologically active substances and affect the aromatic bouquet of the studied plants.

\section{Acknowledgements}

The authors thank colleagues from the National Institute of Grape and Wine "Magarach" and all the supporters of this 
project and the referees for their constructive comments.

\section{Conflicts of Interest}

The authors declare that there are no conflicts of interest regarding the publication of this paper.

\section{References}

1. I. Guterman, M. Shalit, N. Menda, D. Piestun, M. Dafny-Yelin, G. Shalev, E. Bar, O. Davydov, M. Ovadis, M. Emanuel, J. Wang, Z. Adam, E. Pichersky, E. Lewinsohn, D. Zamir, A. Vainstein and D. Weiss, Plant Cell, 14 (2002) 2325.

doi: $10.1105 /$ tpc. 005207

https://elibrary.ru/item.asp?id=23222721

2. E. -K. Choi, H. Guo, J. -K. Choi, S.K. Jang, K. Shin, Y.-S. Cha, Y. Choi, D.-W. Seo, Y.-B. Lee, S.-S. Joo and Y.B. Kim, Lab. Anim. Res., 31 (2015) 148. doi: 10.5625/lar.2015.31.3.148

3. K. Husnu Can Baser, G. Buchbauer, Handbook of Essential Oils: Science, Technology, and Applications, $1^{\text {st }}$ Edition, CRC Press, (2009) 1. doi: 10.1201/9781420063165

4. R. Nowak, M. Olech, Ł. Pecio, W. Oleszek, R. Los, A. Malm and J. Rzymowska, J. Sci. Food. Agric., 94 (2014) 560. doi: $10.1002 /$ jsfa.6294

5. M. Kamijo, T. Kanazawa, M. Funaki, M. Nishizawa and T. Yamagishi, $J$. Biosci. Biotechnol. Biochem., 72 (3) (2008) 773. doi: 10.1271/bbb.70645

6. M.D. Berechet, I. Calinescu, M.D. Stelescu, E. Manaila, G. Craciun, B. Purcareanu, D.E. Mihaiescu, S. Rosca, A. Fudulu, I. G. NiculescuAron and R. Mihai, Rev. Chim., 66(12) (2015) 1986.
https://www.revistadechimie.ro/pdf/BER ECHET D 12 15.pdf

7. M. A. Khan, R. Saeed, S. Gul, M. A. Kamboh, M. I. Khan and S. T. H. Sherazi, Pak. J. Anal. Environ. Chem., 18 (2017) 155. doi: $10.21743 / \mathrm{pjaec} / 2017.12 .16$

8. J. L. Magnard, A. Roccia, J. C. Caissard, P. Vergne, P. Sun, R. Hecquet, A. Dubois, L. H. S. Oyant, F. Jullien, F. Nicolè, O. Raymond, S. Huguet, R. Baltenweck, S. Meyer, P. Claudel, J. Jeauffre, M. Rohmer, F. Foucher, P. Hugueney, M. Bendahmane and S. Baudino, Science, 349 (2015) 81. doi: 10.1126/science.aab0696

9. K. Hosni, A. Kerkenni, W. Medfei, N. B. Brahim and H. Sebei, Hindawi J. Org. Chem. Int., (2010) 7. doi: 10.1155/2010/621967

10. P. Kumari, D. V. S. Raju, K. P. Singh, K. V. Prasad and S. Panwar, Ind. J. Hort., 75 (2018) 349. doi: 10.5958/0974-0112.2018.00060.9

11. L.-G. Feng, C. Chen, L.-X. Sheng, P. Liu, J. Tao, J.-L. Su and L.-Y. Zhao, Molecules, 15 (2010) 8390. doi: 10.3390/molecules 15118390

12. A. Cendrowski, I. Ścibisz, M. Mitek, M. Kieliszek and J. Kolniak-Ostek, J. Food. Qual., 2017 (2017). doi: $10.1155 / 2017 / 7941347$

13. M. Mahboubi, J. Trad. Compl. Med., 6 (2016) 10. doi: 10.1016/j.jtcme.2015.09.005

14. V. Gochev, K. Wlcek, G. Buchbauer, A. Stoyanova, A. Dobreva, E. Schmidt and L. Jirovetz, J. Nat. Prod. Commun., 3 (2008) 1063. doi: 10.1177/1934578X0800300706

15. E. Breitmaier, Terpenes: Flavors, Fragrances, Pharmaca, Pheromones, (2006). doi:10.1002/9783527609949

16. J. B. Harborne FRS, H. Baxter, G. P. Moss, Phytochemical Dictionary: A 
Handbook of Bioactive Compounds from Plants, $2^{\text {nd }}$ Edition, (1998) 1. doi: 10.4324/9780203483756

17. N. A. Mahizan, S. -K. Yang, C. -L. Moo, A. A. -L. Song, C. -M. Chong, C.W. Chong, A. Abushelaibi, S. -H. Erin Lim and K. -S. Lai, Molecules, 24 (2019) 2631. doi: 10.3390/molecules24142631

18. G. Ruberto and M. T. Baratta, J. Food Chem., 69 (2000) 167. doi: 10.1016/S0308-8146(99)00247-2

19. R. Nurzyńska-Wierdak and K. Dzida, Acta Sci. Pol., Hortorum Cultus, 8 (2009) 51.

https://www.researchgate.net/publication 1237225499_Influence_of_plant_density _and_term_of_harvest_on_yield_and_ch emical_composition_of_sweet_marjora m_Origanum_majorana_L

20. V. G. Khrzhanovskiy, Rozy. Filogeniya i sistematika. Spontannye vidy Evropeyskoy chasti SSSR, Kryma i Kavkaza. Opyt i perspektivy ispol'zovaniya [Roses. Race development and taxonomy. Spontaneous species of the European part of the USSR, Crimea and the Caucasus], (1958). (In Russian)

21. O. L. Rubtsova, I. Koval, V. Chyzhankova, T. Buidina and O. Sokolova, Agrobiodiversity for improving Nutrition, Health and Life Quality, (2018) 268. (In Ukrainian) doi:10.15414/agrobiodiversity.2018.258 5-8246.268-276
22. L. B. Chernogorod and B. A. Vinogradova, J. Rast. Res., 42 (2006) 61. (In Russian) https://elibrary.ru/item.asp?id=9186868

23. N. Marko and S. Korsakova, Acta Hortic., 1257 (2019) 175. doi: 10.17660/ActaHortic.2019.1257.25

24. K. J. Naquvi, S. H. Ansari, M. Ali and A. K. Najmi, J. Pharm. Phyt., 2 (2014) 177. http://www.phytojournal.com/archives/2 014/vol2issue5/PartC/20.1.pdf

25. H. Gaussen, VIIIe Congrès International de Botanique, 7\&8 (1954) 125. https://data.bnf.fr/en/crossdocuments/12608151/14612018/page1

26. H. Walter, J. Plant Biol., 68 (1955) 331. (In German) https://onlinelibrary.wiley.com/doi/abs/1 0.1111/j.1438-8677.1955.tb00850.x

27. O. L. Rubtsova, I. V. Koval, N. I. Dzhurenko and O. P. Palamarchuk, J. Plant. Var. Stud. Prot., 13 (2017) 285. (In Ukrainian) doi:10.21498/2518-1017.13.3.2017.110711 